\title{
Spirituality and Quality of Life Among University Students During Covid-19 Pandemic
}

\author{
Ratna Roshida Ab Razak, Zainal Abidin Sanusi, Ahmad Nasir Mohd Yusoff, Nur Ayuni Mohd \\ Isa
}

\begin{abstract}
This research is aimed to examine the quality of students' life during the COVID-19 pandemic. In other words, we want to explore how much spiritual wisdom the students possess which enables them to successfully face the catastrophe. To measure the quality of student life, WHOQoL-BREF questionnaire which is short questionnaire consists of 26 items version of World Health Organization Quality of Life assessment (WHOQoL-100), with some amendments, will be employed. The scope of this cross-sectional study is confined to students who are taking university courses in semester 2, 2019/2020, with the total of 160 samples. This research is considered important because spirituality not only allows humans to respond appropriately in a specific circumstance or scenario, but also to analyze why they are in that state, and how they can adapt, accept and adjust to the situation. Spirituality is the intelligence of the soul, the wisdom with which we can heal ourselves and make ourselves whole, full of sense, intent and value, particularly in times of pandemic, adversity and uncertainty like COVID-19 in relation to the link between superpower, oneself, others and nature.
\end{abstract}

Keywords: Spirituality, COVID-19, University Students, Quality of Life.

\section{INTRODUCTION}

The COVID-19 pandemic tragedy has changed almost all boundaries of life. From East Asia to Europe and around the world, the Corona virus has successfully shown the world its power without discrimination on skin color, life status, wealth, age or nationality. has introduced the Movement Control Order (MCO). With this MCO enforced and extended, students were stripped off their normal routines and forced to avoid social contact. The government's decisions to keep students in their respective locations until the latest directives are issued. Even though students are encouraged to take advantage of the CPP's free time with useful activities such as online learning, exploring the use of the latest technology in learning and so on, this could be considered as easier said than done.

Revised Manuscript Received on September 30, 2020.

* Correspondence Author

Ratna Roshida Ab Razak*, Department of Government and Civilization, Faculty of Human Ecology, Universiti Putra Malaysia, Serdang, Selangor, Malaysia. Email: ratna_razak@upm.edu.my

Zainal Abidin Sanusi, Sejahtera Centre for Sustainability and Humanity, IIUM, Malaysia. Email: zainalsanusi@iium.edu.my

Ahmad Nasir Mohd Yusoff, Department of Government and Civilization, Faculty of Human Ecology, Universiti Putra Malaysia, Serdang, Selangor, Malaysia... Email: ahmadnasir@upm.edu.my

Nur Ayuni Mohd Isa, Department of Government and Civilization, Faculty of Human Ecology, Universiti Putra Malaysia, Serdang, Selangor, Malaysia.Email: nurayuni@upm.edu.my

(c) The Authors. Published by Blue Eyes Intelligence Engineering and Sciences Publication (BEIESP). This is an open access article under the CC BY-NC-ND license (http://creativecommons.org/licenses/by-nc-nd/4.0/)
In an effort to break the COVID-19 chain, the government

Indeed, this unprecedented situation is in dire need for a student to adopt, adapt and adjust to a new situation because it has a great impact on the quality of life as a student. Spirituality of student life is an important issue to tackle during the COVID-19 pandemic because it affects the physical, social and more importantly mental health problem. For this research, the concept quality of life as defined by Bowling (1995) is associated with a positive value as happiness, success, wealth, health and satisfactions. It encompasses major aspects such as health, including mental, physical, emotional and spiritual, as well as material aspect. The WHO also emphasizes the positive side of the concept of health, a positive attitude of society towards the maintenance and Improvement of health as the main condition for a good quality of life. In health-related science, quality of life is used to analyze life satisfaction and to what degree a person measures his or her holistic life experience from a subjective perspective. (Y.H. Yun, 2013) Quality of life has a great deal to do with individual satisfaction with key areas of life which enhances a general sense of physical and emotional well-being. Analysis indicates that this 'Quality of life' term also refers amongst other things to youth, mothers and so on. (Efficace F., 2002) Studies have also found that the significance of quality of living for health care and personal satisfaction is far wider. (Roberts, 1992) Spirituality has been analyzed by a rising array of studies as well as the effect on the quality of life of people. (Mirghafourv M, 2016) Quality of life is this context of discussion is a state of wellbeing, in diverse communities, particularly, university students. Youngster group is considered to be one of the most critical stages of population development and low fitness levels can impact wellbeing during maturity in this process. (Mathew, 2018) Some students resort to spirituality as a coping strategy as a response to the various challenges they face (Castellanos and Gloria 2008). In surveys carried out by the UCLA Higher Education Research Institute in its National Review of the Quest for Significance and Intent of Students in Class. $80 \%$ of respondents said they were interested in spirituality and believed in the sacredness of life; about $66 \%$ acknowledged that their faith was a source of joy; more than $75 \%$ said they trusted in God; more than 66\% accepted that their religious / spiritual convictions provided them with energy, encouragement and guidance; and $75 \%$ said they were satisfied.(Astin, 1999) Such statistics show that spirituality is important for the lives of university students, and stress the critical role of spirituality in higher education. Spirituality can be characterized as the inner, intimate, and emotional manifestation of the divine, which is measured by comfort and peace derived from religion, spiritual nature, and spiritual connection.

Blue Eyes Intelligence Engineering \& Sciences Publication

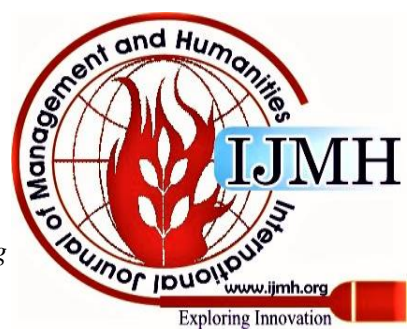




\section{Spirituality and Quality of Life Among University Students During Covid-19 Pandemic}

Spirituality is something that everyone can experience, and it helps us find meaning and purpose in the things we value. It also encourages us to seek the best relationship with ourselves, with others, and with what lies beyond.

The spiritual wellbeing can be defined as a feeling of communicating with others, having meaning and goal in life and having belief and relation with an exalted power. (Hawks, et al, 1995)

\section{RESEARCH METHODOLOGY}

This study employed WHOQoL-BREF questionnaire which is short questionnaire consists of originally 26 items version of World Health Organization Quality of Life assessment (WHOQoL-100). For this article, only the items that are specifically relevant to the issue have been discussed. The scope of the cross-sectional study is confined to students from various faculties, who are taking compulsory university courses in this second semester for the academic year of 2019/2020, with the total of 160 samples..

\section{FINDINGS \& DISCUSSIONS}

This research used the descriptive approach to sum up the percentage of the data represented. Scoring was done according to the percentage of the certain items that are closely related to the spirituality aspects. Spirituality is regarded as having a clear meaning, purpose and value of life through a sense of connection with a transcendence of self, others and superpower, which results in a feeling of inner peace, harmony and satisfaction. In the course of data processing the following three types of relationship emerged, relationship with higher beings, own self and other people. Spirituality go beyond the self: it nurtures sense of purpose, wholeness, peace, and interaction with all others including nature and the cosmos.

According to Danah (2000), spiritual intelligence is a collection of spiritual abilities and resources that arise from the highest degree of human intellectual development, that is to say, transcendental achievement.

\section{A. Spirituality and Relationship}

COVID-19 was moving all of us in ways that we have never been moved, and making us do something that we never did. It stresses us in very odd ways, too. Maybe one of the most tiring things is the lack of clarity all over. It is in this time of pandemic that we will know our inner power, called spirituality. To externalize the sense of spirituality, it is important to express the relationship and interactions between individuals, individuals and social institutions, such as schools and other organizations. Relationships may contribute to an improved sense of identity, a strong social network, active community engagement, enhanced perception of closeness and motivation, access to relevant resources and knowledge of health, exposure to positive modelling, mentoring and participation in pro-social activities. (Cohen \& Wills).

\section{B. Relationship with higher being of Superpower (God)}

7b-How much lesson have you learned from this COVID-19 pandemic, especially related to the SUPERPOWER i.e. God.

160 responses
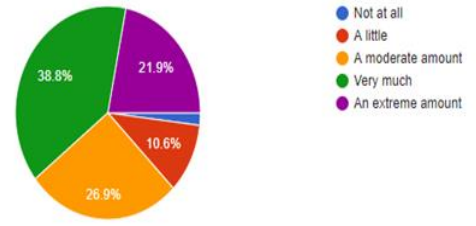

From the above chart we might understand that during the catastrophe $60.7 \%$ of students discovered something relevant to the superpower. Even though the number should be higher, it is sufficient to indicate that certain number of students have learned that there is the kind of relationship.

Spirituality involving a personal connection with a higher being. It follows that when something happens beyond the control, we should accept that there is one force beyond the reach of human beings. A relationship with the superpower (God), a force higher is supposedly a source of energy to humans. It creates a confidence in people that they should cope for all human hardship. Through this relationship, one will have a spiritual perspective that helps him to make sense of life and frame life events properly. (Danah, 2000)

Over the past three decades, many researchers and clinicians see religion as an important way to cope with trauma and distress. (Pargament, 2004) Therefore, nowadays, there is no question that faith, one of the roots of spirituality, is far more important. This period is the best time for each of us to reframe the circumstances through a prism of hope. Positive faith reframing can enable people to overcome difficult times by helping them to perceive a disaster as a chance to grow closer to the superpower or God.

By having a sense of connectedness with the superpower, it will promote a feeling of bonding. In this case many people believe that faith makes them part of something greater than themselves. It can happen by prayer or meditation, or by engaging in religious activities or simply doing things like listening and brisk walking. (Park C.L, 2017).

Spirituality can lessen the impact of the catastrophe on people's wellbeing. Research indicates that confidence serves as a shield for the deleterious effects of a disaster and/or leads to psychological distress in the disaster. Aiet el. (2005), based on their research on 9/11 incident, stronger faith, hope, and spirituality to be inversely correlated with depression and anxiety related to the exposure of direct and indirect 9/11 trauma. Therefore, a great deal of effort should be made to ensure that students return to the superpower for whatever condition beyond their control. All they need to do is embrace it in peace and with an open heart.

\section{Relationship with Own self}

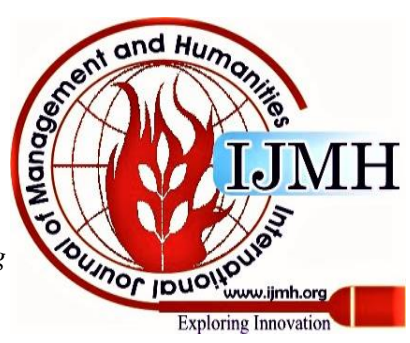


1a-How would you rate your quality of life during $\mathrm{MCO}$ ? 160 responses

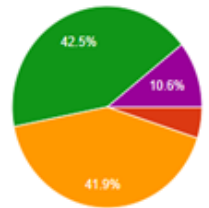

Nearly half of the students, 53.1\% during the lockdown considered their quality of life in 'good and very good' and the other half felt the other way round. Even though some of them were at home and some of them were at the university or private accommodations, they all were lockdown. From this result, we may infer that some students are not going to

It would be normal for the students that involved in the incident like this pandemic to feel some anxiety, panic, depression or disconnect. It's the uncertainty which scares them. They can't get together, and just keep on learning. Their lives have also changed due to loss of earnings or loss of parental income, deterioration of psychological state due to bad news and events such as fear of becoming sick or spreading the disease to one's family.

During this time, students need to speak and interact with their sorrow, anger, and the like, although it can be difficult to get started. These are the kind of treatment they need and they have to take excise. Identify a friend who knows your feelings and supports them, or a trusted teacher, counsellor. (Coles, 1990) In this case, university should play an important role in supplying them with knowledge and skills on how to navigate life during the uncertainties.

3a-To what extent do you feel that emotional pain prevents you from doing what you suppose to do?

160 responses

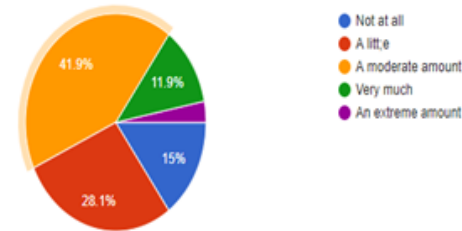

This finding further shows the same phenomenon in which, during to the Movement Control Order, 56.9\% of students felt the emotional pressure that prevented them from doing what they were meant to do. This result shows us that the situation has influenced nearly half the emotions of the students. This uncertainty contributes to a stifling feeling. With constant and endless frustration, whirling and wondering how to get through another day of dealing with all the stuff of daily life, this pandemic has made everybody to go through all kinds of frightening and unpredictable stuff all the time. In reality, this is the best time for them to check and concentrate on themselves, and get in touch with their feelings, focus on both what is tough and what is still sweet to be able to manage the obstacles very well but some will. others and not get in isolation but speak to someone about

carry on, like journaling or doing meditation or just a friendly conversation. (Goleman, 1996) In dealing with uncertainty the first step students should do is to accept that in life, not everything we can control. With this belief in mind, one become more open-minded and realistic and can easily accept the fact that uncertainty is something that is acceptable and bearable. The students need to be reminded that they can do so much thing right now - and that make them strong and not weak. Things are going to unfold soon enough. In the meantime, they are in charge of the way they handle themselves. (Hardy, 1979)

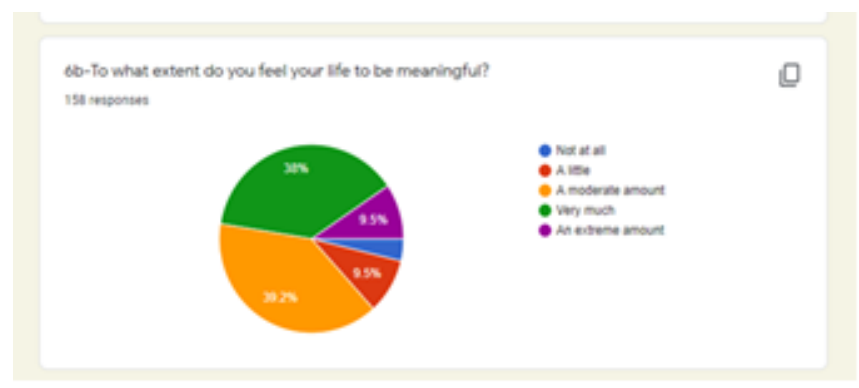

During this uncertain period, only $47.5 \%$ of the students considered their lives to be very meaningful. In general, half of students will embrace the condition and give it significance, but half does not. Spiritual insight helps to someone to understand why one has these interactions and what lesson has he or she learned for his or her spiritual development or growth.

Tension is not particularly dangerous in the short term, according to Pressman (2020), because our bodies are built to cope with short-term flight or battle situations. However, our bodies begin or dysregulate because the stress lasts for a long period of time, around two to three months. If they are unable to move through homeostasis - a stable equilibrium of hormonal systems, then we begin to see social, mental, and hormonal damage. This may be the reason why just 47.5 percent of the students viewed their lives as meaningful. Thus, each and every one would continue to undergo those types of events experiences in life before the necessary learning have accomplished.

\section{Relationship with Others}

110-To what extent do you feel obliged to help people who were affected during the outbreak like front liners, poor people etc?

160 responses
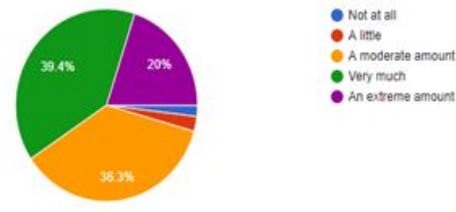

An important part of spirituality is our relationship with other people. $59.4 \%$ felt obligated to aid those affected by the outbreak. A positive indication that students have a spiritual potential is the feeling of helping others.

Published By:

Blue Eyes Intelligence Engineering \& Sciences Publication

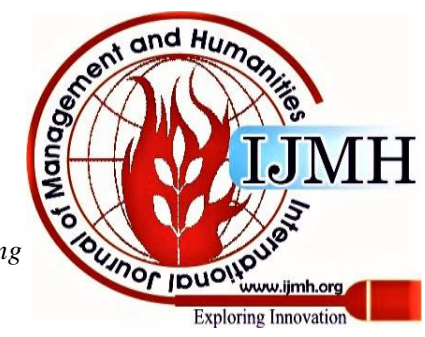


This is because students want to contribute something like good deeds, no matter what form of support, tangible or intangible. This is because the act of kindness will penetrate straight into the hearts and make people bounce in happiness. This is important to view helping others as an equally vital spiritual activity, alongside common items such as prayer, meditation, scripture study, or fasting.

Decades of research have found that mood, anxiety and relationships can affect our stress levels, our immune and digestive systems and whether or not we recover from disease. We understand that calming factors such as social experiences and positive emotions can reverse these processes of stress and help us so we don't get ill. Thus, those processes need to be carefully worked out. (Pressman, 2020)

12C-Do you agree that happiness is found in helping others? 160 responses
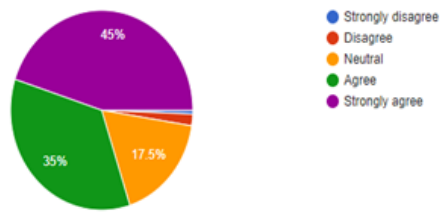

$80 \%$ of students find satisfaction in supporting others. It is a good indicator to show that students possess the dimension of spirituality because they have a clear understanding that it will cultivate the seed of happiness which will grow and become happier people by helping others.

According to Attachment Theory and Neuroscience human being are programmed with a desire for communication. (Anna, 2017) That is why we can see the number is really high, and this is an incentive for students if they have a sharing gift that could really support someone in need. In reality, this is a time to participate by sharing whatever skills they possess.

Many of the major religions of the world also urge their members to take care of others' needs. Buddhism for example, stresses compassion. Islam, as said by the Prophet Muhammad, "The best among you are those who bring greatest benefits to many others." In Judeo-Christian practices, they also promote the needs of children, widows and strangers.

14C-How satisfied are you with your family relationship?

159 responses

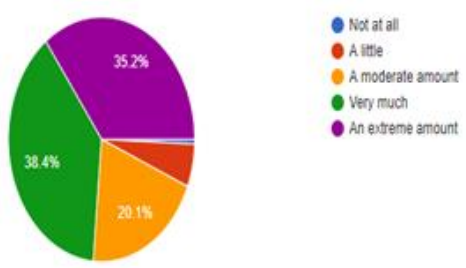

74.6\% students were happy with their families. Spirituality is an essential part of human nature and family life. Cultural principles and practices have driven and nourished cultures over the centuries and through generations Lang (2013) found a strong link between family interaction and spirituality as mechanisms for coping. The ability to regulate emotional experiences in spirituality settings may be the very key to unfolding a positive coping mechanism when drawn to the supernatural in order to achieve quality of life according to the internal normal activity of the attachment system. Parmar and Jogsan (2017) stated that mental health and spiritual intelligence are affected by the family relationship.

Strong or indirect correlations with quality of lfe shows the activation of a paradigm of spiritual resilience which helps in social processes and in dealing with difficult circumstances in life, based on the transcendent relationship.

\section{CONCLUSION}

The results from this study provide a broad view of the spirituality and quality of life during the Covid-19 pandemic among university students Spirituality is best understood by incorporating spiritual perspective that includes defining aspects of faith and individual life. COVID-19 is only one example of turbulence. What is important is that we learned the lesson from it and how we handle it. In this case we managed to understand how much the spiritual wisdom that students possess. This wisdom is a grace or noble attribute by which, no matter what their life may be, students may adapt or blend with others. The adaptable student, whatever his personality, could accommodate himself with others and with all the natural surroundings. This adaptability is a very important quality for effectively leading a life. The COVID-19 pandemic. It taught us, for university-level educators, how to teach students during a catastrophe in order to ensure that their life is carried out harmoniously. University as an organization should have a positive impact on student life, on the life of its workers, and on the community in which it operates. University's primary function is to ensure the creation of healthy graduates in terms of three key components, that is, intellectual (academic), physical, and spiritual. For the moral part, the outcome of the spiritual component can be seen through their behavior and appearance especially during the turmoil like the COVID-19 pandemic. In this case, with the high spirit of inspiration, clarity and health, they could develop resilience and adapt to the new standard. Universities should encourage and cultivate confidence which will contribute to the success of students as a whole. University should ensure that students are produced holistically, taking into account the three major human dimensions, i.e. intellectual, physical, and spiritual. It should be understood the spiritual domain which cuts deeper than the intellectual domain. Today, more emphasis is placed on knowledge-based and information-oriented education that focuses more on students ' academic growth and takes some of their actions and personality away from the other spiritual element. As a result, they are not suitably built to alter life's purpose, meaning, and values. With this pandemic, it is hoped that more spiritual-oriented curriculum will be added. With spirituality, students will be able to look inward (relationship with one's own self to reflect values, wishes, dreams and aspirations), outward (relationship with others as well as with nature and surroundings to represent natural world and climate, human achievement).

Published By:

Blue Eyes Intelligence Engineering

\& Sciences Publication

(C) Copyright: All rights reserved.

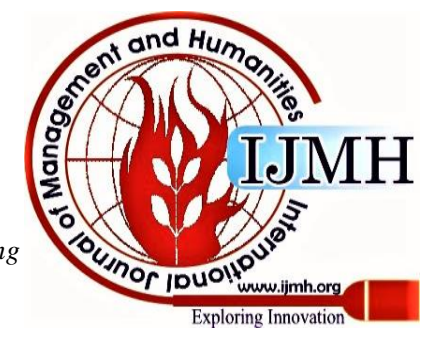


In spirituality we want to develop students with the spirit of always learning something and committed to the quest for meaning, purpose and significance from events in life that life offers and whichever events in life can be interpreted. Greater understanding of the value of spirituality among students will enhance academic capacity to address the spirituality of students, and improve collaborative partnerships between educators and higher learning institutions. Further studies on the relationship between spirituality and quality of life should be carried out in various contexts for the population and health.

\section{ACKNOWLEDGMENT}

The authors received no financial support for the research, authorship, and publication of this article.

\section{REFERENCES}

1. Astin, A. W. (1999). Meaning and spirituality in the lives of college faculty: A study of values, authenticity, and stress. Los Angeles, CA: Higher Education Research Institute, University of California.

2. Ai, A., Cascio, T., Santangelo, L. K., \& EvansCampbell, T., 2005, Hope, meaning, and growth following the September 11, 2001, terrorist attacks. Journal of Interpersonal Violence, 20, 523- 548. doi:10.1177/0886260504272896

3. Coles, Robert, 1990, The Spiritual Life of Children, Houghton Mifflin, Boston.

4. Danah Zohar and Ian Marshall, 2000, SQ, Connecting with our Spiritual Intelligence, Bloomsbury, New York.

5. Goleman, Daniel, 1996, Emotional Intelligence, Bantam Book: New York, London.

6. Hardy, Alastair, 1979, The Spiritual Nature of Man, Oxford University Press, Oxford.

7. Showkeen Bilal Ahmad Gul, et al, "Spirituality a Dimension of All-Round Development of Human Personality and Educational Developments", in Excellence International Journal of Education and Research (Multi- Subject Journal), July 2013, Aligarh Muslim University, India.

8. Richa Banerjeea et al. Family Relationship and Spiritual Intelligence: With Reference to Students of Professional Courses, SSRN- Elsevier.

9. Kenneth I Pargament 1, Harold G Koenig, Nalini Tarakeshwar, June Hahn ill elderly patients: a two-year longitudinal study", Journal Healt., 2004, "Religious coping methods as predictors of psychological, physical and spiritual outcomes among medically h Psychology, Nov;9(6):713-30, doi: 10.1177/1359105304045366.

10. Park, C. L., Holt, C. L., Le, D., Christie, J., \& Williams, Positive and negative religious coping styles as prospective predictors of well-being in African Americans, B. R., Psychology of Religion and Spirituality, 2017.

11. Mathew A. Tkachuck, Stefan E. Schulenberg \& Elicia C. Lair, 2018, "Natural disaster preparedness in college students: Implications for institutions of higher learning" Journal of American College Health, DOI: 10.1080/07448481.2018.1431897.

12. Sarah Pressman, 2020, Covid-19: How to live with uncertainty? in https://www.axa.com/en/magazine/Covid19-crisis-How-to-live-withuncertainty [retrieved on 4th September 2020.

13. Anna Buchheim, et al, Neuroscience of Human Attachment, in Front. Hum. $\quad$ Neurosci., 24 March 2017 https://doi.org/10.3389/fnhum.2017.00136 [retrieved on 23rd August 2020]

14. YH, Lee MK, Park SM, Kim YA, Lee WJ, Lee KS, Choi JS, Hung KH, Do YR, Kim SY, Heo DS, Kim HT, Park SR. Effect of complementary and alternative medicine on the survival and health-related quality of life among terminally ill cancer patients: a prospective cohort study. Ann Oncol. 2013;24(2):489-94.

15. Roberts L, Clifton R. Measuring the cognitive domain of the quality of student life: an Death Studies. instrument for faculties of education. Can J Educ. 1992;17(2):176-191. doi: 10.2307/1495319.

16. Efficace F, Marrone R. Spiritual issues and quality of life assessment in cancer care. 2002;26:743-756. doi: 10.1080/07481180290106526.

17. Lang A. Az Istenhez való kötődés és a vallásos megküzdés szerepe az élettel való elégedettségben. [Impact of attachment to God and religious coping on life satisfaction] Orv Hetil. 2013;154(46):1843-1847. doi: 10.1556/OH.2013.29751.

18. Panzini RG, Maganha C, Rocha NS, Bandeira DR, Fleck MP. Brazilian validation of the Quality of Life Instrument/spirituality, religion and personal beliefs. Rev Saúde Pública. 2011;45(1):153-165. http://www.scielo.br/pdf/rsp/v45n1/en_1765.pdf.

19. Mirghafourvand M, Charandabi SM, Sharajabad FA, Sanaati F. "Spiritual well-being and health-related quality of life in iranian adolescent girls". 2016, Commun Ment Health J. 2(4):484-492. https://link.springer.com/content/pdf/10.1007\%2Fs10597-016-9988-3 .pdfG. O. Young, "Synthetic structure of industrial plastics (Book style with paper title and editor)," in Plastics, 2nd ed. vol. 3, J. Peters, Ed. New York: McGraw-Hill, 1964, pp. 15-64.

20. W.-K. Chen, Linear Networks and Systems (Book style). Belmont, CA: Wadsworth, 1993, pp. 123-135.

21. H. Poor, An Introduction to Signal Detection and Estimation. New York: Springer-Verlag, 1985, ch. 4.

22. B. Smith, "An approach to graphs of linear forms (Unpublished work style)," unpublished.

23. E. H. Miller, "A note on reflector arrays (Periodical style-Accepted for publication)," IEEE Trans. Antennas Propagat., to be published.

24. J. Wang, "Fundamentals of erbium-doped fiber amplifiers arrays (Periodical style-Submitted for publication)," IEEE J. Quantum Electron., submitted for publication.

25. C. J. Kaufman, Rocky Mountain Research Lab., Boulder, CO, private communication, May 1995.

26. Y. Yorozu, M. Hirano, K. Oka, and Y. Tagawa, "Electron spectroscopy studies on magneto-optical media and plastic substrate interfaces(Translation Journals style)," IEEE Transl. J. Magn.Jpn., vol. 2, Aug. 1987, pp. 740-741 [Dig. $9^{\text {th }}$ Annu. Conf. Magnetics Japan, 1982, p. 301].

27. M. Young, The Techincal Writers Handbook. Mill Valley, CA: University Science, 1989.

28. (Basic Book/Monograph Online Sources) J. K. Author. (year, month, day). Title (edition) [Type of medium]. Volume(issue). Available: http://www.(URL)

29. J. Jones. (1991, May 10). Networks (2nd ed.) [Online]. Available: http://www.atm.com

30. (Journal Online Sources style) K. Author. (year, month). Title. Journal [Type of medium]. Volume(issue), paging if given. Available: http://www.(URL)

\section{AUTHORS PROFILE}

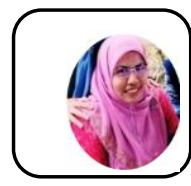

Ratna Roshida Ab Razak, is an Associate Professor of the Department of Government and Civilizational Studies at the University Putra Malaysia. She earned her first degree B. Human Sciences (Hons) 1995 from International Islamic University Malaysia (IIUM), MA (1996) and PhD (2000) from Leeds University, UK. Her areas of interest in research and publication are civilizational studies. spirituality and humanistic psychology which she formalized in her $\mathrm{PhD}$ on this subject, and came out with a book entitled, Understand Al-Mutanabbi: A Humanistic Psychological Approach. Her main research area is about meaning, purpose and value in life. She has presented papers at conferences both home and abroad, published articles and papers in various journals, and contributed a chapter to the book Civilizational Competences and Regional Development in Poland (Warsaw University Press, 2009). She has published in such journals as, British Journal of Arts and Social Sciences, The International Journal of Humanities, KEMANUSIAAN: The Asian Journal of Humanities, The Islamic Quarterly, Akademika, Jurnal Peradaban and so on. She has taught a number of courses such as Islamic and Asian Civilization (TITAS), Ethnic Relation, Critical Thinking, Major Themes in Selected World Religions, Asian Thought: Indian, Japanese and Chinese and, Islamic Thought and Social Changes..

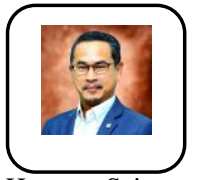

Zainal Abidin Sanusi, is currently Director, Sejahtera Centre for Sustainability and Humanity, International Islamic University Malaysia while serving as an Associate Professor at the Department of Political Science, Kuliyyah of Islamic Revealed Knowledge and Human Science. Prior to this post, he served as Minister Council (Education) at Malaysian High Commission. London. He had also served Deputy Director, Centre for Leadership Training at Higher Education Leadership Academy of the Ministry of Education Malaysia.

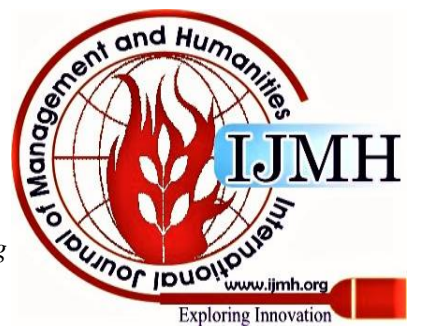


He has a Ph.D. in International Studies from Waseda University, Japan and M.A. in International Relations from International University, Niigata, Japan. He has also spent one-year postdoctoral study at UN University Institute of Advanced Studies, Yokohama, Japan doing research on the multilateral environmental agreement. His area of academic specialization is governance and education for sustainable development. He has participated in many international workshop and conferences on the subject as both speaker and invited participant and discussant. In his previous post as the Deputy Director at the Academy, Zainal had directly involved in planning, organizing and delivering training program, seminar and workshop on various higher education leadership and governance matters designed for the university leaders.

He was a Visiting Professor at Graduate School of Frontier Science, University of Tokyo engaging in teaching and research on conceptual and organizational challenges in implementing sustainability science in higher education institutions. His current research interests are Sustainability Science, Education for Sustainable Development and Public Policy Analysis.

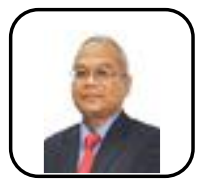

Dr. Hj Ahmad Nasir Mohd Yusoff, is a Senior Lecturer, Department of National Studies and Civilization, Faculty of Human Ecology. UPM, Serdang Selangor. Early Education at SRK Rambutan Rendang, SMK (A) Ma'had Muhammadi, Kota Bharu Kelantan and continued his studies at the Doctor of Philosophy, (Philosophy and Civilization), 2010. (UKM), MA (History \& Islamic Civilization), 2005. University Malaya (UM) and Bachelor's Degree (Qur'an and Tafsir), 1996. University of Malaya (UM). He has produced 216 publications including books (29), chapters in books (10), proceedings (40), journals (30), seminars and conferences (45), Copyright (2), unpublished reading materials (50), etc. other publications (7). Among his research involves FRGS (5), GIPP (3), GP-IPM (1), GP-PUTRA (1) and RUGS (1) grants. He is a member of Darus Syifa 'cooperative, a member of the cooperative Amal Bintulu Iqra' Center (BIC), a member of Darus Syifa 'Islamic Medicine, Medicine and Treatment and a member of Darus Salam Islamic Medicine Among the highest index achievements in Google Scholar involve citation (30), h-index 3 (3) and i10-index (1). Other achievements such as producing 29 translation books (Tafsir al Maraghi \& Kitab al Bidayah wal al Nihayah), won 47 awards including gold (10), silver (23) and bronze (14) medals in internationally integrated teaching and learning innovation competitions and national, coordinating and development of PutraMOOC, Vice Chancellor Fellowship Award 2018 (Best Teaching) -2019 -UPM-Best Teaching Category- (Arts and Social Sciences) and Putra Innocreative Awards (Best Innocreative Educator In PutraMOOC). -PITCL-2019

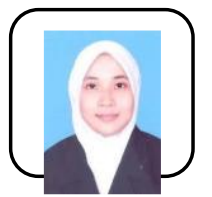

Nur Ayuni Binti Mohd Isa, senior lecturer at the Department of Government and Culture, Faculty of Human Ecology, Universiti Putra Malaysia, Politics and Culture. She holds a degree in Human Development from Universiti Putra Malaysia, a Master in Science in Politics and a Doctor of Philosophy in Politics \& Administration. Policy and economy , political party, political relations, and coalition government were her current research priorities. She is still fond of studying 'Dayak's youth engagement in Sarawak politics'. Her latest publication is 'Student involvement radical politics: A study in Sultan Idris University of Education (UPSI)' in' the International Journal of Advanced Science and Technology.

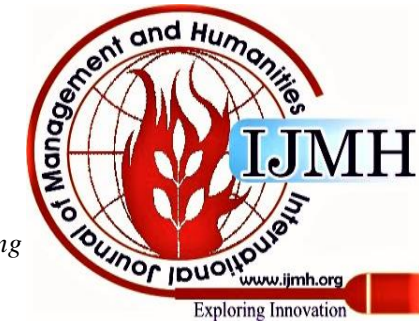

